\title{
Effects of a continuum of care intervention on frail older persons life satisfaction: a randomized controlled study
}

\author{
Helene Berglund, Henna Hasson, Karin Kjellgren and Katarina Wilhelmson
}

\author{
Linköping University Post Print
}

Tweet

N.B.: When citing this work, cite the original article.

Original Publication:

Helene Berglund, Henna Hasson, Karin Kjellgren and Katarina Wilhelmson, Effects of a continuum of care intervention on frail older persons life satisfaction: a randomized controlled study, 2015, Journal of Clinical Nursing, (24), 7-8, 1079-1090.

http://dx.doi.org/10.1111/jocn.12699

Copyright: Wiley: 12 months

http://eu.wiley.com/WileyCDA/

Postprint available at: Linköping University Electronic Press

http://urn.kb.se/resolve?urn=urn:nbn:se:liu:diva-117370 


\section{Effects of a continuum of care intervention on frail older persons' life satisfaction: A randomized controlled study}

\section{Authors:}

Helene Berglund, RN, MSc, PhD student, Institute of Health and Care Sciences, The Sahlgrenska Academy at University of Gothenburg, 40530 Gothenburg, Sweden; Vårdalinstitutet, The Swedish Institute for Health Sciences, 22100 Lund, Sweden; Henna Hasson, PhD, Researcher, Karolinska Institute, Medical Management Centre (MMC), 17177 Stockholm, Sweden; Vårdalinstitutet, The Swedish Institute for Health Sciences, 22100 Lund, Sweden; Karin Kjellgren, RN, PhD, Professor, Institute of Health and Care Sciences, The Sahlgrenska Academy at University of Gothenburg, 40530 Gothenburg, Sweden; Department of Medical and Health Sciences, Linköping University, 58183 Linköping, Sweden; Katarina Wilhelmson, MD, Associate Professor, Department of Public Health and Community Medicine/Social Medicine, Institute of Medicine, The Sahlgrenska Academy at University of Gothenburg, 40530 Gothenburg, Sweden; Vårdalinstitutet, The Swedish Institute for Health Sciences, 22100 Lund, Sweden

Correspondence:

Helene Berglund

Institute of Health and Care Sciences, The Sahlgrenska Academy at University of Gothenburg, 40530 Gothenburg, Sweden

Telephone: +46317866107

Fax and email addresses:

HB: $\quad$ +46317866110 helene.berglund@gu.se

HH: $\quad+4686405001$ henna.hasson@ki.se

KK: $\quad+46011037659$ karin.kjellgren@liu.se

KW: +4631 162847 katarina.wilhelmson@socmed.gu.se

The work reported here was supported by grants from Vårdalinstitutet, The Swedish Institute for Health Sciences. 


\section{ABSTRACT}

Aims and objectives. The aim of this study was to analyse effects of a comprehensive continuum of care (intervention group) on frail older persons' life satisfaction, as compared to those receiving usual care (control group). The intervention included geriatric assessment, case management, interprofessional collaboration, support for relatives and organizing of care-planning meetings in older persons' own homes.

Background. Improvements in older persons' subjective well-being have been shown in studies including care planning and coordination by a case manager. However, effects of more complex continuum of care interventions on frail older persons' life satisfaction are not well explored.

Design. Randomized controlled study.

Methods. The validated LiSat-11 scale was used in face-to-face interviews to assess older persons' life satisfaction at baseline and at three, six and 12 months after the baseline. The odds ratio for improving or maintaining satisfaction was compared for intervention and control groups from baseline to three-month, three-month to six-month as well as six-month to 12-month follow-ups.

Results. Older persons who received the intervention were more likely to improve or maintain satisfaction than those who received usual care, between six and 12 month followups, for satisfaction regarding functional capacity, psychological health and financial situation. 
Conclusions. A comprehensive continuum of care intervention comprising several components had a positive effect on frail older persons' satisfaction with functional capacity, psychological health and financial situation.

Relevance to clinical practice. Frail older persons represent a great proportion of the persons in need of support from the health care system. Health care professionals need to consider continuum of care interventions' impact on life satisfaction. As life satisfaction is an essential part of older persons' well-being, we propose that policy makers and managers promote comprehensive continuum of care solutions.

Keywords: care planning, case management, continuum of care, interprofessional collaboration, life satisfaction, older persons, randomized controlled study 


\section{INTRODUCTION}

Life satisfaction is closely related to the concepts of quality of life and subjective well-being. It has been suggested to be a sub-theme of quality of life and subjective well-being (Diener $e t$ al. 1999, Sirgy 2012). Life satisfaction can be measured in order to collect information in fields such as emotion-related and social aspects of life where instruments measuring quality of life are weak (Borg et al. 2010). The concept of life satisfaction includes satisfaction with life as a whole and satisfaction with specific domains, such as family life, leisure, financial situation and health (Borg et al. 2010, Diener et al. 1999).

\section{BACKGROUND}

The relationship between life satisfaction and age has been addressed in several studies, with contradictory findings. Some studies reported that life satisfaction is stable across life (Diener et al. 1999, Hamarat et al. 2002) and others found a positive relationship between age and life satisfaction (Horley \& Lavery 1995, Prenda \& Lachman 2001). However, Mroczek and Spiro (2005) and Berg et al. (2009) found a decrease in level of life satisfaction in old age. Life satisfaction among frail older persons appears to have been investigated rarely (Borg et al. 2006). However, in a recent study Wilhelmson et al. (2013) found that frailty was of more importance than old age, as regards the negative relationship to life satisfaction. Frailty refers to a multi-system deterioration of the reserve capacity at older ages, resulting in increased vulnerability to stressors (Fried et al. 2004). As regards quality of life, this was investigated by Bilotta et al. (2010), who found that frail older persons reported a worse overall quality of life than non-frail older persons. Knowledge of life satisfaction in frail older persons is of 
importance for nurses and other health care professionals, as they care for these persons to a great extent.

Outcomes of care interventions provide important information about quality of care. Essential outcomes comprise evaluations by the older persons themselves (Donabedian 2003, Dubois et al. 2013), such as evaluations of life satisfaction. Effects of continuum of care interventions on frail older persons' life satisfaction seem not to have been frequently evaluated in earlier studies. However, measurement of quality of life was included in several evaluations of continuum of care interventions. Lin et al. (2009) reported better quality of life among older persons with hip fracture who received individualized, comprehensive care planning and postdischarge home visits, as compared to a control group receiving usual care. In a meta-analysis Preyde et al. (2009) concluded that augmented care planning, including interdisciplinary involvement and a designated care coordinator, resulted in a moderate effect on quality of life. On the other hand, older persons rated equal quality of life in an intervention including individualized care planning managed by a coordinator as compared to that of a control group (Weinberger et al. 1996), and respectively better quality of life in the control group in an intervention comprising augmented care planning and interdisciplinary co-ordination (Sulch et al. 2000). In other studies subjective well-being was evaluated. A systematic review of studies comprising care planning and coordination by a case manager showed consistent evidence of improvements on older persons' subjective well-being (You et al. 2012).

In this study the effects of a comprehensive continuum of care intervention on life satisfaction were examined. Previous studies on the effects of this intervention have shown positive results as regards older persons' views of quality of care (Berglund et al. 2013), as well as frailty and activities of daily living (Eklund et al. 2013). The implementation of the 
intervention has also been studied, showing positive results on implementation fidelity (Hasson 2010, Hasson et al. 2012) and attention to involved actors' commitment to the intervention (Duner et al. 2011).

The aim of this study was to analyse effects of a comprehensive continuum of care (intervention group) on frail older persons' life satisfaction as compared to those receiving usual care (control group). Our hypothesis was that a comprehensive continuum of care intervention, including several methods, such as coordination by a case manager, interprofessional teamwork and care-planning meetings in the older persons' own homes, might have a positive effect on frail older persons' life satisfaction. This paper presents the study in accordance with the consort recommendations (Consort 2013).

\section{METHODS}

\section{Intervention and participants}

The study is part of a larger interdisciplinary project entitled Continuum of Care for Frail Elderly People (Wilhelmson et al. 2011). The aim of the project was to increase quality of care and maintain functional ability among frail older persons as well as to increase costeffectiveness. The project was planned in collaboration between municipal care, primary care and hospital care in a city with approximately 60,000 inhabitants in Sweden.

Inclusion criteria for participating in the project were: older persons living in their own homes, who visited the emergency department, aged 80 and older or 65 to 79 with a need for assistance in at least one activity of daily living and a minimum of one chronic illness. Exclusion criteria were: severe acute illness (with immediate need of medical treatment), 
dementia or severe cognitive impairment (according to medical record or judgement made by the registered nurses with geriatric expertise at the emergency department) and palliative care (as documented in the medical record). The intention was that the participants should comprise a sample of frail older persons at a high risk of future health care consumption. The older persons were invited to participate by two registered nurses with geriatric expertise at the emergency department. Those accepting were randomized to intervention group or control group. A system of sealed opaque envelopes was used (Wilhelmson et al. 2011).

In the intervention group, several methods to establish a comprehensive continuum of care were applied:

- The registered nurse with geriatric expertise made an assessment of the need for health/social care and rehabilitation at the emergency department.

- The assessment was transferred to the hospital ward, if the older person moved to a ward. It was also sent to a municipal interprofessional team, including case manager (registered nurse), social worker, physiotherapist and/or occupational therapist.

- The case manager coordinated the planning for discharge together with the older person, hospital professionals and the municipal interprofessional team.

- The case manager contacted the relatives, if approved by the older person, to offer them support and advice and to inform/involve them in the care planning.

- A care-planning meeting was organized in the older person's own home, a few days after discharge. The meeting was held by the case manager together with the municipal interprofessional team and it took place regardless of whether the older person needed home care services or not. 
- If the older persons returned home directly after visiting the emergency department they were offered a care-planning meeting a few days after the emergency visit in the home as well.

- Within one week after the care-planning meeting the case manager contacted the older person, for follow-up of needs and care.

- In collaboration with the older person the case manager decided how often to follow up the planned care. Mostly the case manager contacted the older person a minimum of once a month for 12 months and was available for ongoing support.

- After six months, a new care-planning meeting was held in the older person's home, if needed.

- In case of new admission to hospital, a new care-planning meeting in the older person's home was conducted, after discharge.

The control group received the usual care, which did not include the components comprised in the intervention group. The care-planning meeting/discharge planning for those in the control group took place at hospital if new home care services were needed, which was the usual routine. These meetings were run by hospital professionals and a regular municipal interprofessional team, including social worker, municipal nurse, occupational therapist and/or physiotherapist. No care-planning meeting was held for those coming home directly after visiting the emergency department (Wilhelmson et al. 2011).

All participants signed a written informed consent form. The study was approved by the Regional Ethical Review Board in Gothenburg, Sweden, registration number 413-08. It was registered at Clinical Trials Gov: NCT01260493. 


\section{Data collection}

Baseline measurement was usually made within a few days after hospital discharge, and follow-ups were performed at three, six and 12 months after the baseline measurement. Questionnaires were used, and the items were asked in face-to-face interviews by $\mathrm{PhD}$ students (including the first author), project assistants and members of the interprofessional team. All interviewers had experience of elderly care and were well trained in interviewing and assessing, according to the guidelines for the different outcome measurements. The interviews took place in the older persons' homes, both for the intervention and the control groups. The questions and the response alternatives were read to the older persons. Additionally the response alternatives were shown on a paper, if needed. If the respondents did not completely understand the question, the interviewers explained it thoroughly. The interviewers used a manual, where the scales and items in the questionnaire were explained in more detail. The project managers also organized meetings with all interviewers, in order to reach consensus about the meaning of items. The baseline and follow-up data were collected between October 2008 and December 2011.

\section{Outcome measures}

The questionnaire contained several validated scales and items about life satisfaction, illness, functional ability, health, medication and quality of care (Wilhelmson et al. 2011). Frailty was assessed as weakness, fatigue, weight loss, reduced physical activity, impaired balance, reduced gait speed, visual impairment and impaired cognition. For details about the frailty indicators and measurement methods see Wilhelmson et al. 2011. We regarded the older persons as frail if they fulfilled three or more frailty indicators (Fried et al. 2004). The primary outcome measure in this 
paper is life satisfaction. The validated LiSat-11 scale was used to measure older persons' life satisfaction (Borg et al. 2010, Fugl-Meyer et al. 1991). It contains eleven items, including satisfaction with life as a whole as well as satisfaction with work, financial situation, leisure, friends and acquaintances, sexual life, functional capacity, family life, partner relationship, physical health and psychological health. Each item has six response alternatives: "1-very dissatisfied, 2-dissatisfied, 3-rather dissatisfied, 4-rather satisfied, 5-satisfied and 6-very satisfied". The instrument can validly be dichotomised into not being satisfied (grade 1-4) versus being satisfied (grade >4) (Borg et al. 2010, Fugl-Meyer et al. 1991), which was also used in the present study.

The LiSat-11 scale has been validated in a representative sample of men and women aged 1874 years, in Sweden. The item "life as a whole" has been shown to correlate to all other items (Borg et al. 2010). It has adequate discriminate and specificity validities as well as test-retest reliability (Fugl-Meyer et al. 1991).

\section{Statistics}

A power calculation was done, with knowledge of prevalence rates of functional abilities which had been estimated in another health-promoting intervention study of the research group conducted with other persons in the same region (Dahlin-Ivanoff et al. 2010). However, the prevalence rates were for less frail older persons than those in our study. Therefore we presumed lower functional status and higher standard deviance. This power calculation was based on the balance scale, which was one of the primary outcome variables, range 0-56. For the intervention group the assumed mean was 32 and for the control group 28 (15\% difference). The assumed standard deviation was 8 in both groups. To be able to detect a 
difference between the intervention and control groups with a two-sided test and with a significance level of alpha $=0.05$ and $80 \%$ power we would need a minimum of 65 persons in each group (Wilhelmson et al. 2011).

Differences between the intervention and control groups regarding base-line characteristics were calculated using chi-square tests (gender, age, cohabitant/living alone, dependency on help in ADL and illness) and Mann-Whitney U-test (frailty), respectively. The proportion of respondents being satisfied at baseline and the follow-ups was compared for intervention and control groups for each life satisfaction item. The proportion of respondents improving or maintaining satisfaction was compared for intervention and control groups from baseline to three-month, three-month to six-month and six-month to 12-month follow-ups. Additionally, the proportions from baseline to six- and respectively 12-month follow-ups were analysed. The odds ratio was calculated to compare outcomes between groups. A two-sided p-value of $<0.05$ and a $95 \%$ confidence interval (CI) were set as statistical significance. Statistical analyses were performed using SPSS statistical software package, version 19 for Windows (Chicago: SPSS Inc.).

Intention-to-treat (ITT) was applied; this involves an effort to keep respondents in the groups to which they were randomized. Strategies for dealing with missing data involved imputation of the missing values, i.e. estimating what the value would be if it was not missing (Polit \& Gillespie 2010). We used different methods for imputation, depending on the reason for missing value (Committee for Medicinal Products for Human Use 2010, Polit \& Gillespie 2010). The median change of deterioration was calculated for each item, for baseline to threemonth, three-month to six-month as well as six-month to 12-month follow-ups, for those who participated in the follow-ups. For respondents who declined to continue before any of the 
follow-ups the respective median change of deterioration was imputed on each missing value, as suggested in previous studies (Eklund et al. 2013, Gustafsson et al. 2012). This was done because we assumed that respondents who declined to continue in our study had deteriorated health. Worst case imputation, attributing the worst value to missing cases, was done for respondents who died before any of the follow-ups (Eklund et al. 2013, Gustafsson et al. 2012, Polit \& Gillespie 2010).

For respondents who completed the study but did not have observed values at baseline or any of the follow-ups and for internal missing we involved the respondent's own obtained values on the same outcomes at a different point of time (Polit 2010). Missing values at baseline were replaced with the values of the respective outcome for that respondent at the next follow-up (Engels \& Diehr 2003). If there were missing values between two measurement occasions with observed values a value between the observed values (mean) was imputed. Missing values which appeared at 12-month follow-up were replaced with the values of the outcome at the previous follow-up (Polit 2010). However, in a few cases the median deterioration was imputed, if the respondent showed deteriorating health and functional ability, measured as I-ADL/P-ADL, physical activity and balance. Furthermore, a comparison was made between analysis including the imputed values and complete case analysis, showing similar trends.

\section{RESULTS}

A total of 343 older persons were invited to participate, and 159 (46\%) of them declined, mostly because the study seemed too demanding. Others declined later or died before baseline measurement. Baseline data were collected for 161 older persons (intervention $n=85$, control 
n=76) (Wilhelmson et al. 2011). For details about enrolment and allocation see Wilhelmson et al. (2011). Attrition before each follow-up and respondents included in the present analyses are presented in Figure 1.

(Insert Figure 1 about here)

The attrition at three months was about $15 \%(\mathrm{n}=24)$. At six months the attrition from baseline was approximately $19 \%(n=30)$, and at 12 months $22 \%(n=36)$. The attrition rate was about the same in intervention and control groups at three- and 12-month follow-ups.

\section{Description of respondents and attrition}

Baseline characteristics of respondents are presented in Table 1. There were no significant differences between the intervention and control groups regarding baseline characteristics (gender, age, cohabitant/living alone, dependency on help in ADL, illness and frailty). Median amount of fulfilled frailty indicators was four in both groups, indicating that the respondents comprised a sample of frail older persons (Fried et al. 2004).

(Insert Table 1 about here)

Baseline characteristics were checked for respondents who completed all follow-ups and for attrition, at three, six and 12 months. There were no significant baseline differences between respondents and attrition for gender, age and cohabitant/living alone at any of the follow-ups. For baseline differences regarding I-ADL/P-ADL there was a pattern of larger proportions of dependency in $\geq 1$ activity for the attrition, at all three follow-ups. The difference was statistically significant for I-ADL at three months and 12 months. There was also a pattern of higher baseline illness (proportion of $\geq 2$ severe/constant disability or extremely severe clinical 
problem) in the attrition compared to respondents, at all three follow-ups (non-significant). For baseline differences on frailty there were significantly larger amounts of fulfilled frailty indicators in the attrition at all three follow-ups.

\section{Life satisfaction}

The items comprising satisfaction with work, sexual life as well as partnership had a large amount of missing values, as many of the respondents did not consider these relevant for themselves. These items were therefore excluded from the analyses. For the remaining eight items there was a pattern of higher proportions of persons being satisfied in the intervention group as compared to the control group at baseline. However, the odds ratio was only statistically significant for the satisfaction with family life item. The proportions of persons being satisfied at baseline and corresponding odds ratio for each item are presented in Table 2.

(Insert Table 2 about here)

At the 12-month follow-up there were higher proportions of persons being satisfied in the intervention group for all eight items, but the difference was significant only for physical health (OR 2.57, CI 1.19-5.55). For psychological health there was a significant difference between the groups at six-month follow-up in favour of the control group (OR 0.45, CI 0.240.86). (Data not shown).

For all eight items there were greater proportions of respondents who improved or maintained satisfaction in the intervention group as compared to the control group between the six- and 12- month follow-ups. Statistically significant odds ratios were detected for three of the items: 
functional capacity, psychological health and financial situation. There was also a pattern of higher proportions improving or maintaining satisfaction in the control group from baseline to three-month and three-month to six-month follow-ups. For psychological health, at three- to six-month follow-ups, a statistically significant odds ratio in favour of the control group was found. Proportions of respondents improving or maintaining life satisfaction are presented in Table 3. (Insert Table 3 about here)

The additional analysis of proportions improving or maintaining satisfaction from baseline to six-month follow-up showed higher proportions in control group for almost all items (not statistically significant). However, from baseline to 12-month follow-up the proportions improving or maintaining satisfaction was higher in intervention group for almost all items (not statistically significant). (Data not shown).

\section{DISCUSSION}

There was a positive effect of the continuum of care intervention on older persons' life satisfaction. The older persons receiving the intervention were about two to three times more likely to improve or maintain satisfaction than those who received usual care, between sixand 12-month follow-ups, for functional capacity, psychological health and financial situation. The findings are discussed in more detail below, together with suggestions for implications for research and practice.

There are apparently few evaluations of frail older persons' life satisfaction in previous continuum of care interventions. However, our results are in line with similar studies, evaluating quality of life and subjective well-being. In a meta-analysis of studies including 
augmented care planning, interdisciplinary involvement and a designated care coordinator, a moderate effect on quality of life could be seen (Preyde et al. 2009). These evaluations were made up to three months after baseline. In a systematic review You et al. (2012) showed that care planning and coordination by a case manager resulted in improvements in older persons' subjective well-being.

We could not detect any effects of the intervention from baseline to three-month or threemonth to six-month follow-ups. This can be related to the differences between groups at baseline. The proportion of older persons who were satisfied was higher in the intervention group at baseline, for most items. However, the difference was significant for only one of the items. This may be due to the fact that the intervention already had some effect at baseline. As the older persons were not in any condition to answer the items at hospital, the baseline measurement was done in their homes, a few days after discharge. The higher proportions of persons being satisfied in the intervention group at baseline could make it more difficult to detect differences in favour of the intervention between baseline and three- and six-month follow-ups, which is discussed in more detail under methodological considerations.

The positive effects found in our study on functional capacity, psychological health and financial situation appear to be important aspects of life satisfaction for older persons. These aspects are known to correlate with overall life satisfaction (Borg et al. 2010), and they seem to be interconnected to each other, forming complex relationships. Health and functional capacity have been shown to be especially important for very old persons (90+) (Hillerås et al. 2001). In a longitudinal study on changes in life satisfaction it was concluded that health and functional capacity were significantly associated with life satisfaction among older persons aged above 85 (Bowling et al. 1993). However, follow-up analyses indicated a 
relative stability in life satisfaction over time (Bowling et al. 1996). In addition, as regards quality of life, results of a cross-sectional study showed that being frail as well as being dependent on help in activities of daily living were associated with a worse quality of life among older persons (65+) (Bilotta et al. 2010).

In this study the proportion of respondents improving or maintaining satisfaction with functional capacity was significantly higher in the intervention group (between six and 12 months) as compared to the control group. The subjective measure on functional capacity shows the same result as more objective measures, as our results are in line with the assessments of ADL made in this project (Eklund et al. 2013). Eklund et al. (2013) found that the intervention succeeded in improving ADL independence up to one year. In addition, another continuum of care intervention for older persons with hip fracture, including a personcentred approach with interdisciplinary care plans and collaboration, showed positive results as regards restored ADL levels in the intervention group (Olsson et al. 2009).

One explanation for the positive effects on satisfaction with functional capacity might be that a physiotherapist and/or occupational therapist was part of the municipal interprofessional team and participated in care planning in the older persons' own homes. They assessed the need of rehabilitation, observed how the older persons managed at home and made sure that they had the appropriate technical aids. Initially, the registered nurses at the emergency department made an assessment of the need for health/social care as well as rehabilitation, which probably also indirectly contributed to the older persons' satisfaction. In addition, the steps taken by the case manager, such as coordination of care planning and follow-up of the older persons' needs and care, may have resulted in higher satisfaction among the older persons. 
Decrease in functional capacity seems in turn to be associated with poor psychological health. Deterioration of ADL scores has been shown to be consistently associated with high levels of worry and depression (Bowling \& Grundy 1997). Borg et al. (2008) concluded that the consequences of reduced functional capacity, such as feeling worried, are significantly associated with low life satisfaction. The positive results seen in the present study regarding psychological health might be a result of the outcomes on older persons' perceptions of quality of care. Older persons in the intervention group perceived higher quality in all aspects of care planning than did those receiving the usual care, and they also had better knowledge of whom to contact during a period of up to one year (Berglund et al. 2013). This may have contributed to the positive results in this study as regards psychological well-being, between six and 12 months. If the older persons felt satisfied about care planning and knew whom to contact in different situations it probably made them feel comfortable and secure. The case manager was available for advice and support and contacted the older person at least once a month. In addition a new care-planning meeting was held after six months, if needed. This in turn might have influenced the older persons' psychological health positively.

The effects of the current intervention on satisfaction with financial situation seem to be less evident from prior studies than those of functional capacity and psychological health. AbuBader et al. (2003) found no correlation between financial situation and life satisfaction in a sample of frail older persons (60+). However, Berg et al. (2009) found that financial situation and life satisfaction were related, among older persons aged $80+$, on a cross-sectional level. In our study there were, as far as we know, no changes in the older persons' real financial situations. The explanation for the positive results might be that the older persons in the intervention group perceived their financial situation as more satisfactory, because of better 
psychological health. They may have adapted better to their real financial situation. However, the financial situation also needs to be considered in the care of frail older persons, as income may affect their health and possibilities to satisfy personal needs.

\section{Methodological considerations}

The strength of this study was that it targeted frail older persons who are in special need of high-quality coordination (Bauer et al. 2009, Naylor \& Keating 2008). Frail older persons are not easy to include in intervention and follow-up studies, but this study was longitudinal and follow-ups were made up to one year. Furthermore, it was a controlled randomized study and the respondents in the intervention group received the intervention components as planned, with only small modifications (Hasson et al. 2012).

From baseline to 12 -month follow-up about $22 \%$ of the respondents died or declined to continue participation, which could imply a risk to the internal validity. We assumed that the older persons who declined had deteriorated health, and therefore they considered the study to be too demanding. Analyzing only complete cases would not have been appropriate, as it could result in bias. We investigated if there were differences between respondents who fulfilled all follow-ups and attrition regarding baseline characteristics. There was a pattern of higher dependency on help in I-ADL/P-ADL and illness (baseline characteristics) in the attrition as compared to respondents who fulfilled all follow-ups. However, the differences were only statistically significant for I-ADL at baseline for the attrition at three- and 12month follow-ups. In addition, the attrition at all follow-ups was significantly frailer at baseline. This indicates that the attrition was not random, and supports our choice of imputation methods for missing values for those who died or declined to continue. 
A limitation of the study was that the intervention started shortly before the baseline measurement. The baseline measurement was done in the older persons' homes, as it was not ethically correct to tire the older persons with questionnaires at the emergency department. It is likely that the intervention had already had an effect at baseline, as there was a pattern of higher proportions of persons being satisfied in intervention group at baseline.

Additionally, there was a pattern of higher proportions of participants who improved or maintained their satisfaction in the control group from baseline to three-month and threemonth to six-month follow-ups. This might be explained by the fact that the older persons in the intervention group were more satisfied at baseline. The control group had more space to improve or maintain satisfaction and, for the intervention group, more improvements were required to find a difference in their favour. This may have contributed to detectable differences later in time, from six-month to 12-month follow-up, in favour of the intervention group.

A limitation of the study is that the LiSat-11 scale (Borg et al. 2010, Fugl-Meyer et al. 1991) was not developed to target older persons. However, it was validated in a representative sample of persons aged 18-74 (Borg et al. 2010), and most items are also reasonably valid in older ages. In a previous study Wilhelmson et al. (2013) concluded that the scale was applicable to older persons, but probably more sensitive among younger persons. Especially the items on sexual life and partnership have large amounts of missing values in previous studies on older persons' life satisfaction (Wilhelmson \& Eklund 2013, Wilhelmson et al. 2013). 


\section{CONCLUSION AND RELEVANCE TO CLINICAL PRACTICE}

A comprehensive continuum of care intervention had a positive effect on frail older persons'

life satisfaction. The older persons receiving a comprehensive continuum of care intervention were more likely to improve or maintain satisfaction than those who received usual care between six and 12 months after baseline, for functional capacity, psychological health and financial situation. The intervention included several components, such as geriatric assessment by registered nurses at the emergency department, a designated case manager (registered nurse) in the municipality, interprofessional teamwork, support for relatives and care-planning meetings in the older persons' own homes. Frail older persons constitute a major portion of the persons in need of nursing and support from the health care system. Thus nursing staff and other health care professionals need to consider the knowledge of care interventions' impact on different aspects of life satisfaction. As life satisfaction is a fundamental part of frail older persons' subjective well-being, we suggest that policymakers and managers further promote comprehensive continuum of care solutions. 


\section{REFERENCES}

Abu-Bader SH, Rogers A \& Barusch AS (2003) Predictors of life satisfaction in frail elderly. Journal of Gerontological Social Work 38, 3-17. doi:10.1300/J083v38n03_02

Bauer M, Fitzgerald L, Haesler E \& Manfrin M (2009) Hospital discharge planning for frail older people and their family. Are we delivering best practice? A review of the evidence. Journal of Clinical Nursing 18, 2539-2546. doi:10.1111/j.13652702.2008.02685.x

Berg AI, Hoffman L, Hassing LB, McClearn GE \& Johansson B (2009) What matters, and what matters most, for change in life satisfaction in the oldest-old? A study over 6 years among individuals 80+. Aging and Mental Health 13, 191-201. doi: 10.1080/13607860802342227

Berglund H, Wilhelmson K, Blomberg S, Dunér A, Kjellgren K \& Hasson H (2013) Older people's views of quality of care: A randomised controlled study of continuum of care. Journal of Clinical Nursing 22, 2934-2944. doi: 10.1111/jocn.12276

Bilotta C, Bowling A, Case A, Nicolini P, Mauri S, Castelli M \& Vergani C (2010) Dimensions and correlates of quality of life according to frailty status: a crosssectional study on community-dwelling older adults referred to an outpatient geriatric service in Italy. Health and Quality of Life Outcomes 8, 56. doi:10.1186/1477-7525-856

Borg C, Fagerström C, Balducci C, Burholt V, Ferring D, Weber G, Wenger C, Holst G \& Hallberg IR (2008) Life satisfaction in 6 European countries: the relationship to health, self-esteem, and social and financial resources among people (Aged 65-89) with reduced functional capacity. Geriatric Nursing 29, 48-57. doi:10.1016/j.gerinurse.2007.05.002

Borg C, Hallberg IR \& Blomqvist K (2006) Life satisfaction among older people (65+) with reduced self-care capacity: the relationship to social, health and financial aspects. Journal of Clinical Nursing 15, 607-618. doi: 10.1111/j.1365-2702.2006.01375.x

Borg T, Berg P, Fugl-Meyer K \& Larsson S (2010) Health-related quality of life and life satisfaction in patients following surgically treated pelvic ring fractures. A prospective observational study with two years follow-up. Injury 41, 400-404. doi:10.1016/j.injury.2009.11.006

Bowling A, Farquhar M, Grundy E \& Formby J (1993) Changes in life satisfaction over a two and a half year period among very elderly people living in London. Social Science and Medicine 36, 641-655.

Bowling A, Farquhar M \& Grundy E (1996) Associations with changes in life satisfaction among three samples of elderly people living at home. International Journal of Geriatric Psychiatry 11, 1077-1087. doi: 10.1002/(sici)1099-1166(199612)11:12<1077::aid-gps466>3.0.co;2-d

Bowling A \& Grundy E (1997) Activities of daily living: changes in functional ability in three samples of elderly and very elderly people. Age and Ageing 26, 107-114. doi: 10.1093/ageing/26.2.107

Committee for Medicinal Products for Human Use (2010) Guideline on Missing Data in Confirmatory Clinical Trials. European Medicines Agency, London.

Consort, Consolidated Standards of Reporting Trials. Available at: http://www.consort-statement.org/ (accessed October 2013).

Dahlin-Ivanoff S, Gosman-Hedstrom G, Edberg A-K, Wilhelmson K, Eklund K, Duner A, Ziden L, Welmer A-K \& Landahl S (2010) Elderly persons in the risk zone. Design of a multidimensional, health-promoting, randomised three-armed controlled trial for 
"prefrail" people of 80+ years living at home. BMC Geriatrics 10, 27.

doi:10.1186/1471-2318-10-27

Diener E, Suh EM, Lucas RE \& Smith HL (1999) Subjective well-being: Three decades of progress. Psychological Bulletin 125, 276-302. doi: 10.1037/0033-2909.125.2.276

Donabedian A (2003) An introduction to quality assurance in health care. Oxford University Press, New York.

Dubois C-A, D'Amour D, Pomey M-P, Girard F \& Brault I (2013) Conceptualizing performance of nursing care as a prerequisite for better measurement: a systematic and interpretive review. BMC Nursing 12, 7. doi:10.1186/1472-6955-12-7

Duner A, Blomberg S \& Hasson H (2011) Implementing a continuum of care model for older people - results from a Swedish case study. International Journal of Integrated Care 11, e136. URN:NBN:NL:UI:10-1-101653 / ijic2011-136

Eklund K, Wilhelmson K, Gustafsson H, Landahl S \& Dahlin-Ivanoff S (2013) One-year outcome of frailty indicators and activities of daily living following the randomised controlled trial; "Continuum of care for frail older people". BMC Geriatrics 13, 76. doi: 10.1186/1471-2318-13-76

Engels JM \& Diehr P (2003) Imputation of missing longitudinal data: a comparison of methods. Journal of Clinical Epidemiology 56, 968-976. doi: http://dx.doi.org/10.1016/S0895-4356(03)00170-7

Fried LP, Ferrucci L, Darer J, Williamson JD \& Anderson G (2004) Untangling the concepts of disability, frailty, and comorbidity: implications for improved targeting and care. The Journals of Gerontology: Series A. Medicine and Social Sciences 59, 255-263. doi: 10.1093/gerona/59.3.M255

Fugl-Meyer AR, Bränholm I-B \& Fugl-Meyer KS (1991) Happiness and domain-specific life satisfaction in adult northern Swedes. Clinical Rehabilitation 5, 25-33. doi: $10.1177 / 026921559100500105$

Gustafsson S, Eklund K, Wilhelmson K, Edberg AK, Johansson B, Kronlof GH, GosmanHedstrom G \& Dahlin-Ivanoff S (2012) Long-term outcome for ADL following the health-promoting RCT - Elderly persons in the risk zone. The Gerontologist 53, 654663. doi: 10.1093/geront/gns 121

Hamarat E, Thompson D, Aysan F, Steele D, Matheny K \& Simons C (2002) Age differences in coping resources and satisfaction with life among middle-aged, young-old, and oldest-old adults. Journal of Genetic Psychology 163, 360-367. doi: 10.1080/00221320209598689

Hasson H (2010) Systematic evaluation of implementation fidelity of complex interventions in health and social care. Implementation Science 5, 67. doi: 10.1186/1748-5908-567

Hasson H, Blomberg S \& Duner A (2012) Fidelity and moderating factors in complex interventions: a case study of a continuum of care program for frail elderly people in health and social care. Implementation Science 7, 23. doi: 10.1186/1748-5908-7-23

Hillerås PK, Jorm AF, Herlitz A \& Winblad B (2001) Life satisfaction among the very old: A survey on a cognitively intact sample aged 90 years or above. The International Journal of Aging and Human Development 52, 71-90. doi: 10.2190/B8NC-D9MQKJE8-UUG9

Horley J \& Lavery JJ (1995) Subjective well-being and age. Social Indicators Research 34, 275-282. doi: 10.1007/bf01079200

Lin PC, Wang CH, Chen CS, Liao LP, Kao SF \& Wu HF (2009) To evaluate the effectiveness of a discharge-planning programme for hip fracture patients. Journal of Clinical Nursing 18, 1632-1639. doi: 10.1111/j.1365-2702.2008.02695.x 
Linn BS, Linn MW \& Gurel L (1968) Cumulative illness rating scale. Journal of the American Geriatrics Society 16, 622-626.

Miller MD, Paradis CF, Houck PR, Mazumdar S, Stack JA, Rifai AH, Mulsant B \& Reynolds III CF (1992) Rating chronic medical illness burden in geropsychiatric practice and research: Application of the Cumulative Illness Rating Scale. Psychiatry Research 41, 237-248. doi: http://dx.doi.org.ezproxy.ub.gu.se/10.1016/0165-1781(92)90005-N

Mroczek DK \& Spiro A (2005) Change in life satisfaction during adulthood: Findings from the Veterans Affairs Normative Aging Study. Journal of Personality and Social Psychology 88, 189-202. doi: http://dx.doi.org/10.1037/0022-3514.88.1.189

Naylor M \& Keating SA (2008) Transitional care. American Journal of Nursing 108, 58-63. doi: 10.1097/01.NAJ.0000336420.34946.3a

Olsson LE, Hansson E, Ekman I \& Karlsson J (2009) A cost-effectiveness study of a patientcentred integrated care pathway. Journal of Advanced Nursing 65, 1626-1635. doi: 10.1111/j.1365-2648.2009.05017.x

Polit DF (2010) Statistics and data analysis for nursing research. 2nd edn. Pearson, Boston, Mass.

Polit DF \& Gillespie BM (2010) Intention-to-treat in randomized controlled trials: recommendations for a total trial strategy. Research in Nursing and Health 33, 355368. doi: 10.1002/nur.20386

Prenda KM \& Lachman ME (2001) Planning for the future: a life management strategy for increasing control and life satisfaction in adulthood. Psychology and Aging 16, 206216. doi: http://dx.doi.org/10.1037/0882-7974.16.2.206

Preyde M, Macaulay C \& Dingwall T (2009) Discharge planning from hospital to home for elderly patients: a meta-analysis. Journal of Evidence-Based Social Work 6, 198-216. doi: 10.1080/15433710802686898

Sirgy MJ (2012) The psychology of quality of life: hedonic well-being, life satisfaction, and eudaimonia. Springer, Dordrecht. Available at:

http://link.springer.com.ezproxy.ub.gu.se/book/10.1007\%2F978-94-007-4405-9 (accessed 6 November 2013)

Sulch D, Perez I, Melbourn A \& Kalra L (2000) Randomized controlled trial of integrated (managed) care pathway for stroke rehabilitation. Stroke 31, 1929-1934. doi: 10.1161/ 01.STR.31.8.1929

Weinberger M, Oddone EZ \& Henderson WG (1996) Does increased access to primary care reduce hospital readmissions? Veterans Affairs Cooperative Study Group on Primary Care and Hospital Readmission. New England Journal of Medicine 334, 1441-1447. doi: 10.1056/NEJM199605303342206

Wilhelmson K, Duner A, Eklund K, Gosman-Hedstrom G, Blomberg S, Hasson H, Gustafsson H, Landahl S \& Dahlin-Ivanoff S (2011) Continuum of care for frail elderly people: Design of a randomized controlled study of a multi-professional and multidimensional intervention targeting frail elderly people. BMC Geriatrics 11, 24. doi: 10.1186/1471-2318-11-24

Wilhelmson K \& Eklund K (2013) Positive effects on life satisfaction following healthpromoting interventions for frail older adults: a randomized controlled study. Health Psychology Research 1, e12. doi:10.4082/hpr.2013.e12

Wilhelmson K, Fritzell E, Eklund K \& Dahlin-Ivanoff S (2013) Life satisfaction and frailty among older adults. Health Psychology Research (accepted).

You EC, Dunt D, Doyle C \& Hsueh A (2012) Effects of case management in community aged care on client and carer outcomes: a systematic review of randomized trials and comparative observational studies. BMC Health Services Research 12, 395. doi: 10.1186/1472-6963-12-395 
Table 1. Gender, age, cohabitant/living alone, dependency on help in ADL, illness and frailty for the intervention and control groups at baseline $(n=161)$

\begin{tabular}{|c|c|c|c|}
\hline & $\begin{array}{l}\text { Intervention } \\
\text { group } \\
\mathrm{n}(\%)\end{array}$ & $\begin{array}{l}\text { Control } \\
\text { group } \\
\mathrm{n}(\%)\end{array}$ & $\begin{array}{l}\mathrm{p} \text {-value } \\
\text { between } \\
\text { groups }\end{array}$ \\
\hline \multicolumn{4}{|l|}{ Gender } \\
\hline male & $38(45)$ & $34(45)$ & 1.00 \\
\hline female & $47(55)$ & $42(55)$ & \\
\hline \multicolumn{4}{|l|}{ Age } \\
\hline $65-79$ & $20(24)$ & $18(24)$ & 1.00 \\
\hline$\geq 80$ & $65(76)$ & $58(76)$ & \\
\hline Cohabitant* & $37(43)$ & $30(40)$ & 0.72 \\
\hline Living alone & $48(57)$ & $46(60)$ & \\
\hline \multicolumn{4}{|l|}{ ADL } \\
\hline dependent in $\geq 1$ activity in I-ADL & $66(79)$ & $55(73)$ & 0.56 \\
\hline dependent in $\geq 1$ activity in $\mathrm{P}-\mathrm{ADL}$ & $27(32)$ & $23(31)$ & 0.98 \\
\hline Missing responses & 1 & 1 & \\
\hline \multicolumn{4}{|l|}{ Illness } \\
\hline $\begin{array}{l}\leq 1 \text { severe/constant disability or } \\
\text { extremely severe clinical problem } * *\end{array}$ & $61(72)$ & $60(79)$ & 0.38 \\
\hline $\begin{array}{l}\geq 2 \text { severe/constant disability or } \\
\text { extremely severe clinical problem } * *\end{array}$ & $24(28)$ & $16(21)$ & \\
\hline \multirow[t]{2}{*}{ Frailty*** } & Median (range) & Median (range) & \\
\hline & $4(0-7)$ & $4(1-7)$ & 0.41 \\
\hline
\end{tabular}

I-ADL, instrumental activities of daily living: housework, shopping, community mobility and meal preparation;

P-ADL, personal activities of daily living: bathing, dressing, toileting, functional transferring and eating.

*Mostly living with partner, in a few cases with sibling or child.

** rated as number 3 or 4 on Cumulative Illness Rating Scale for Geriatrics (CIRS-G) (Linn et al. 1968, Miller et al. 1992).

***Amount of fulfilled frailty indicators, assessed as weakness, fatigue, weight loss, reduced physical activity, impaired balance, reduced gait speed, visual impairment and impaired cognition. 
Table 2. Proportions (\%), Odds ratio (OR), $95 \%$ Confidence Interval (CI), and p-value for persons being satisfied at baseline

\begin{tabular}{lllllll}
\hline \hline Satisfaction with & \multicolumn{2}{l}{ Intervention } & \multicolumn{2}{l}{ Control } & & \\
& $\%$ & OR & $\%$ & OR & $95 \%$ CI & p-value \\
\hline Life as a whole & 36 & 0.87 & 40 & 1 & $0.46-1.65$ & 0.67 \\
\hline Financial situation & 63 & 1.04 & 62 & 1 & $0.54-1.97$ & 0.92 \\
\hline Leisure & 52 & 1.61 & 40 & 1 & $0.86-3.03$ & 0.14 \\
\hline Friends and acquaintances & 75 & 1.82 & 62 & 1 & $0.93-3.59$ & 0.08 \\
\hline Functional capacity & 64 & 1.59 & 53 & 1 & $0.84-3.00$ & 0.15 \\
\hline Family life & 83 & 2.29 & 68 & 1 & $1.08-4.85$ & $0.03^{*}$ \\
\hline Physical health & 33 & 1.67 & 22 & 1 & $0.82-3.40$ & 0.15 \\
\hline Psychological health & 61 & 1.10 & 59 & 1 & $0.58-2.07$ & 0.77 \\
\hline
\end{tabular}


Table 3. Proportion (\%), Odds ratio (OR), $95 \%$ Confidence Interval (CI), and p-value for improving or maintaining life satisfaction between baseline and three-month, three-month and six-month, respectively six-month and 12-month follow-ups

\begin{tabular}{|c|c|c|c|c|c|c|}
\hline \multirow[t]{2}{*}{ Satisfaction with } & \multicolumn{2}{|c|}{ Intervention } & \multicolumn{3}{|c|}{ Control } & \multirow[b]{2}{*}{$\mathrm{p}$-value } \\
\hline & $\%$ & OR & $\%$ & OR & $95 \% \mathrm{CI}$ & \\
\hline \multicolumn{7}{|l|}{ Life as a whole } \\
\hline Baseline-three-month & 72 & 0.93 & 74 & 1 & $0.46-1.88$ & 0.84 \\
\hline Three-six-month & 59 & 0.75 & 66 & 1 & $0.39-1.43$ & 0.38 \\
\hline Six-12-month & 78 & 1.88 & 66 & 1 & $0.93-3.80$ & 0.08 \\
\hline \multicolumn{7}{|l|}{ Financial situation } \\
\hline Baseline-three-month & 65 & 0.67 & 74 & 1 & $0.34-1.31$ & 0.24 \\
\hline Three-six-month & 70 & 0.67 & 78 & 1 & $0.33-1.37$ & 0.27 \\
\hline Six-12-month & 77 & 2.08 & 62 & 1 & $1.04-4.14$ & $0.04 *$ \\
\hline \multicolumn{7}{|l|}{ Leisure } \\
\hline Baseline-three-month & 61 & 0.90 & 64 & 1 & $0.47-1.71$ & 0.74 \\
\hline Three-six-month & 65 & 0.88 & 68 & 1 & $0.45-1.70$ & 0.70 \\
\hline Six-12-month & 70 & 1.31 & 64 & 1 & $0.67-2.54$ & 0.43 \\
\hline \multicolumn{7}{|l|}{ Friends and acquaintances } \\
\hline Baseline-three-month & 64 & 0.82 & 68 & 1 & $0.42-1.58$ & 0.54 \\
\hline Three-six-month & 69 & 0.73 & 75 & 1 & $0.36-1.47$ & 0.38 \\
\hline Six-12-month & 71 & 1.52 & 62 & 1 & $0.78-2.94$ & 0.22 \\
\hline \multicolumn{7}{|l|}{ Functional capacity } \\
\hline Baseline-three-month & 64 & 0.77 & 70 & 1 & $0.39-1.49$ & 0.43 \\
\hline Three-six-month & 71 & 0.71 & 78 & 1 & $0.35-1.45$ & 0.35 \\
\hline Six-12-month & 75 & 2.39 & 55 & 1 & $1.22-4.67$ & $0.01 *$ \\
\hline \multicolumn{7}{|l|}{ Family life } \\
\hline Baseline-three-month & 68 & 0.54 & 80 & 1 & $0.26-1.12$ & 0.10 \\
\hline Three-six-month & 72 & 0.89 & 74 & 1 & $0.44-1.80$ & 0.74 \\
\hline Six-12-month & 78 & 1.50 & 70 & 1 & $0.73-3.10$ & 0.27 \\
\hline \multicolumn{7}{|l|}{ Physical health } \\
\hline Baseline-three-month & 65 & 0.71 & 72 & 1 & $0.36-1.40$ & 0.32 \\
\hline Three-six-month & 69 & 0.89 & 71 & 1 & $0.45-1.76$ & 0.74 \\
\hline Six-12-month & 72 & 1.61 & 62 & 1 & $0.83-3.14$ & 0.16 \\
\hline \multicolumn{7}{|l|}{ Psychological health } \\
\hline Baseline-three-month & 71 & 1.13 & 68 & 1 & $0.58-2.23$ & 0.72 \\
\hline Three-six-month & 59 & 0.24 & 86 & 1 & $0.11-0.53$ & $0.00 *$ \\
\hline
\end{tabular}




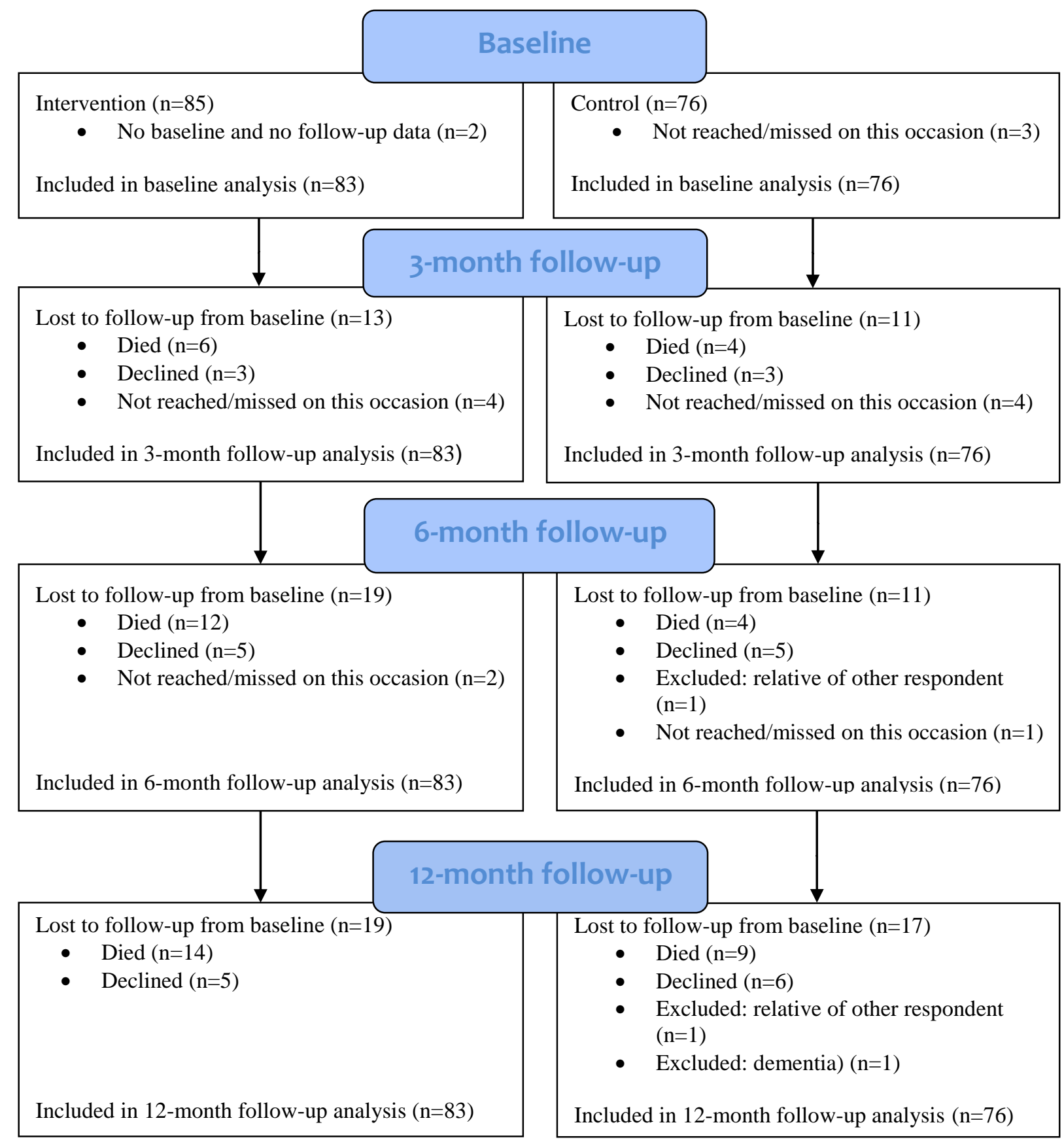

Figure 1. Respondents and attrition in the study 